\title{
¿Qué hace un geógrafo hoy? Análisis crítico y reflexiones para un debate impostergable (caso argentino)
}

\author{
What does a geographer do today? Critical analysis and \\ reflections for an urgent debate (Argentine case)
}

\section{Dante Edin Cuadra ${ }^{1}$}

Fecha de recibido: 28 de agosto de 2020

Fecha de aceptado: 29 de marzo de 2021

\section{Resumen}

El objetivo de este artículo es reflexionar sobre el papel que cumplen los geógrafos en la actualidad, en un contexto caracterizado por grandes, variados y permanentes cambios en el espacio geográfico, los cuales invitan a repensar y redirigir, tanto la disciplina como el quehacer de sus cultores. La metodología empleada consistió en organizar el trabajo analítico en cuatro ejes orientadores: la necesaria autocrítica de los geógrafos sobre su desempeño en la sociedad, la comprensión cabal del contexto en el que se mueven, la toma de conciencia acerca del potencial de la disciplina y de los geógrafos y, por último, el desafío de involucramiento en sus comunidades y territorios. Los resultados ponen en evidencia algunas concepciones, prácticas y omisiones que caracterizaron tradicionalmente, tanto a la disciplina como a sus realizadores, que indujeron a la sociedad a incorporar ideas erróneas sobre qué es la geografía y qué hacen los geógrafos. Consiguientemente, se plantea la necesidad de superar ciertos aspectos acuñados en el ejercicio de la 
docencia, la investigación y la aplicación. Entre las conclusiones, se destacan: la urgencia de revisar los planes de estudios de las carreras de geografía, priorizar el desarrollo de investigaciones vinculadas a las problemáticas actuales (no siempre visibles), jerarquizar la geografía como profesión y, asimismo, cubrir el gran vacío existente en el ámbito de la geografía aplicada. Ello conduciría al logro de una geografía científicamente más significativa y socialmente más comprometida.

Palabras clave: Geografía, globalización, enseñanza, investigación, planificación.

\section{Abstract}

The objective of this article is to reflect on the role that geographers play today, in a context characterized by large, varied and permanent changes in the geographical space, which invite to rethink and redirect, both the discipline and the task of their cultivators. The methodology used was to organize the work in four guiding axes: the necessary self-criticism of geographers about their performance in society, the full understanding of the context in which they move, awareness of the potential of the discipline and the geographers and, finally, the challenge of involvement in their communities and territories. The results highlight some conceptions, practices and omissions that traditionally characterized both the discipline and its cultivators, which induced society to incorporate misconceptions about what geography is and what geographers do. Consequently, the need to overcome certain aspects coined in the exercise of teaching, research and application is raised. Among the conclusions, the following stand out: the urgency of reviewing the curricula of geography careers, prioritizing the development of research linked to current (not always visible) issues, rank geography as a profession, and also covering the great void existing in the field of applied geography. This would lead to the achievement of a scientifically more meaningful and socially more committed geography.

Key words: Geography, globalization, teaching, research, planning.

\section{Introducción}

La geografía, como conocimiento utilitario y cotidiano, está enraizada con la misma historia de la humanidad, pues la propia supervivencia de los grupos sociales ha necesitado siempre de conocimientos detallados sobre los territorios habitados y habitables, así como la localización de recursos para la satisfacción de necesidades básicas, el comportamiento de los ciclos naturales y las posibilidades de desplazamiento eficiente y seguro hacia otras tierras. 
Se trata, por tanto, de una necesidad vital, tal como lo expresan Chiozza y Carballo (2006, p. 38) al sostener que “...el conocimiento geográfico se inicia en las culturas primitivas por la necesidad de conocer su ambiente para asegurar su supervivencia".

Como campo científico la geografía constituyó gran parte de su basamento entre fines del siglo XVIII y la última parte de la centuria siguiente, gracias a aportes como los de Humboldt y Ritter, pero su desarrollo riguroso y sistematizado se consolidó con el paso del tiempo (Estébanez, 1992). No obstante, hasta el día de hoy mucha gente sigue preguntándose qué es exactamente lo que estudia esta ciencia y, fundamentalmente, qué hacen los geógrafos.

En pleno siglo XXI la geografía no ha logrado visibilizar plenamente su rol dentro de la sociedad y, por lo general, las personas la asocian a una asignatura escolar descriptiva, memorística y poco atractiva. Asimismo, el término "geógrafo" a muchas personas les parece una rareza, al menos en Argentina, dado que la figura más percibida por el colectivo social es la del profesor en geografía. Sin embargo, esta disciplina ha experimentado cambios profundos en las últimas décadas y, en el contexto actual, tanto la geografía como los geógrafos, poseen un enorme potencial de desarrollo y muchas contribuciones para hacer, que la sociedad de nuestro tiempo merece conocer imperiosamente. Con esa intención se ha elaborado el presente trabajo, el cual se estructura en cuatro grandes tópicos que se presentan más adelante.

\section{Antecedentes}

Son muchos los autores que, desde la geografía o fuera de ella, han expuesto sus puntos de vista, análisis, reflexiones y críticas en torno a la disciplina, sobre todo en sus aspectos epistemológicos y metodológicos. La diversidad de posiciones, tanto sobre la naturaleza de su constructo-cognoscitivo, como su ubicación, roles y funciones que le competen en el campo científico, radica en la amplitud que presenta su objeto de estudio y, también, en las diferentes concepciones o enfoques que coexisten en su interior, vinculados con paradigmas claramente diferenciados. Justamente, el debate interno, más los cuestionamientos provenientes de otras disciplinas, han convertido a la geografía en una ciencia dinámica, en permanente reacomodación, sobre todo desde mediados del siglo XX en adelante. Dentro de la extensa nómina de autores que, gracias a sus planteos, críticas y propuestas, han contribuido al debate y al desarrollo teórico y metodológico de la geografía, puede nombrarse a Schaefer (1953), Hartshorne (1959), Tuan (1974), Lacoste (1976), Randle (1977), George (1979), Gómez Mendoza (1982), García Ballesteros (1986), Capel (1988), Hagget (1994), Santos (1995), Harvey (1998), Claval (2002), Masey $(1993,2005)$ y Soja (2010), sólo por citar algunos. Lo cierto es que, en la 
actualidad, el debate sigue abierto y ello es un claro indicio de que la geografía se presenta como una ciencia viva, abierta y en proceso de fortalecimiento.

\section{Marco teórico}

En 1883, Richthofen definió a la geografía como ciencia de la superficie terrestre y de los hechos y fenómenos que están en relación de causalidad con ella (Plans, 1984). Muchos años después Baulig (1948) se preguntó ¿es una ciencia la geografía?, llegando a una respuesta negativa. En el transcurso del tiempo, la geografía experimentó notables cambios y cultivó distintas tradiciones geográficas, no obstante en la segunda mitad del siglo XX, gran parte del establishment aceptó al espacio geográfico como categoría conceptual aglutinante y continente de otras categorías (tales como región, paisaje o lugar), asignándole el estatus de objeto de estudio de la disciplina. "A mediados del siglo XX el espacio geográfico comienza a ocupar un lugar central en el discurso geográfico" (Blanco, 2009, p. 38). Fue a partir de entonces que la geografía "experimentó una renovación en sus principios conceptuales de gran significación" (Daus, 1978, p. 91). Ello implicó correr definitivamente el punto gravitacional hacia el componente antrópico (cuyos antecedentes encontramos ya en Vidal de la Blache y en Ratzel), en virtud de que el espacio geográfico es concebido en función de los grupos humanos y no de la mera naturaleza.

Con el tiempo, la geografía logró afirmarse a través del aporte de nuevos enfoques, métodos y una vasta producción científica, sobre todo en los ámbitos universitarios y organismos de investigación. Al decir de Pickenhayn (1994, p. 148), hoy la geografía goza de "auténtica autoconvicción", sin necesidad de adaptar su discurso al de otras ciencias, ni "continuar con la gimnasia de crisis" en la que ha estado ocupada durante mucho tiempo. Ello no significa que tenga todo resuelto en asuntos teóricos, epistemológicos y metodológicos, pero sí que trabaja con preocupación y ahínco en esa línea, como lo hacen las demás ciencias que, sin ser perfectas tienen el atributo de ser perfectibles.

De acuerdo con Holt Jensen (1992, pp. 196-197), la geografía tiene como fortaleza el hecho de que en su interior "Coexisten escuelas de pensamiento alternativas y su diversidad es algo beneficioso porque ofrece una comprensión de dimensiones más amplias", de modo que "deberíamos subrayar la heterogeneidad de la geografía con sus ricas y polifacéticas tradiciones". En la actualidad este aspecto cobra mayor relevancia, en virtud de que lo "...posmoderno pasa a significar pluralismo de lenguajes, de modelos, de formas de expresión" (Berciano, 1998, p. 12).

El mundo actual, caracterizado por la consolidación de un sistema planetario o global, donde la contracción del tiempo ha supuesto, 
simultáneamente, la contracción del espacio (el significado de las distancias como elemento de separación ha dejado de tener el peso evidenciado en los siglos precedentes), llevó al planteo de si se trataba del final de la geografía, cosa que afortunadamente no ocurrió. "En este contexto adquiere sentido la reflexión geográfica y la búsqueda de herramientas para la interpretación de estos fenómenos, la elaboración de una representación o modelo capaz de ayudar a entender el mundo en que vivimos" (Ortega Valcárcel, 2000, pp. 506508).

Sucede

...que en la vida social y académica coexisten... una pluralidad de posiciones teóricas, marcos interpretativos, opiniones, criterios y formas de acción. La agenda temática de una geografía renovada nos enfrenta permanentemente a cuestiones y dilemas no sólo intelectuales, cognitivos o metodológicos, sino políticos, sociales, valorativos y éticos (Gurevich, 2009, p. 184).

Por tanto, entendida la ciencia como un campo dinámico de comprensión, conformación y contribución a la realidad y a las problemáticas de cada época, queda claro que su evolución se halla ligada a la posibilidad de admitir y generar críticas, interpelaciones y debates en su seno, lo que le garantiza, por un lado, la necesaria retroalimentación y, por otro, la adecuación a los parámetros externos (realidad) que aseguren su desarrollo.

\section{Materiales y métodos}

Dentro de la abundante literatura existente en materia de teoría, epistemología y crítica geográficas, se han seleccionado y analizado algunos trabajos que aportan luz a este horizonte de cambios, como contexto del trabajo reflexivo que se presenta en este artículo. Dicha reflexión se organiza en torno a cuatro aspectos axiales relativos al papel que le cabe a los geógrafos en las primeras décadas del siglo XXI, pensados como generadores de futuros e ineludibles debates dentro de la comunidad de geógrafos, y ellos son:

- La necesaria autocrítica sobre el rol que desempeñan en la sociedad.

- La comprensión cabal del contexto en el que se mueven.

- La toma de conciencia acerca del potencial de la disciplina y del quehacer de los geógrafos.

- El desafío de involucramiento en sus comunidades y territorios.

Los cambios abruptos y acelerados que se observan en el espacio geográfico, sobre todo en las últimas décadas (1980 en adelante), impelidos por el sistema global, la revolución tecnológica, la multiplicación de datos disponibles y la instantaneidad de su comunicación, han influido fuertemente en los ámbitos culturales, sociales, económicos, políticos e institucionales 
(incluidos los académicos), además de generar nuevas problemáticas e incertidumbres de diferentes tipos y escalas en los territorios.

En este escenario de convergencias y pujas de múltiples tendencias, ideologías y formas de comprensión de la realidad (cosmovisiones contrapuestas), los geógrafos se hallan subsumidos en una manifiesta hiperactividad que, muchas veces, se muestra errática y carente de reflexión y análisis teórico.

\section{Resultados}

\section{La necesaria autocrítica sobre el rol que los geógrafos desempeñan en la sociedad (lo que hacen y lo que debieran hacer)}

"¿Qué es ser un geógrafo?" preguntó el Principito al anciano en la novela escrita por Antoine de Saint-Exupéry, publicada por primera vez en 1943. Allí se identifica al geógrafo con alguien que escribe libros enormes, que sabe mucho sobre mares, ríos, ciudades, montañas y desiertos, pero que desconoce lo que hay a su alrededor, pues no abandona su escritorio, tampoco realiza trabajos de campo y, solamente, se nutre de los informes que le brindan los exploradores, aunque en este caso no disponía de ellos, completándose así el absurdo (De Saint-Exupéry, 2008).

Tal concepción no dista demasiado de la que tienen muchas personas en la actualidad sobre el geógrafo: un investigador de gabinete que toma datos provenientes de otras disciplinas, que escribe a partir de ellos y que repite en las aulas lo que encuentra en los textos, en total desconexión con la realidad en la cual vive. Esa conducta ha sido la de muchos individuos formados en la disciplina a lo largo del siglo XX y no se halla erradicada totalmente en los tiempos actuales. No por casualidad la sociedad ha asimilado conceptos tales como la figura solitaria del investigador científico y el escaso conocimiento del docente de geografía - sobre todo de la escuela media- sobre su propio entorno (que lo lleva a enseñar puntillosamente sobre hechos y fenómenos de países o continentes lejanos, pasando por alto las características propias de la ciudad, pueblo o paraje en que residen sus alumnos o evitando las visitas guiadas y los trabajos de campo en el lugar).

Podríamos preguntarnos ¿qué han hecho mal o qué no hicieron los geógrafos para que la concepción expresada por el prestigioso novelista tuviese tanta distorsión (o acaso ironía) respecto de lo que sí debiera hacer un geógrafo? Para colmo, el autor no era alguien del vulgo, sino una persona educada en un país de la vanguardia cultural europea como Francia, cuna de la geografía regional y de grandes maestros de la disciplina como Paul Vidal de la Blache, Emmanuel De Martonne, Jean Brunhes, Jules Sion, Maximilien Sorre, André Cholley, Eliseo Réclus, Albert Demangeon y muchos 
más. ¿Significa que los geógrafos no supieron comunicar correctamente lo que hacían?, ¿que su trabajo se tornó irrelevante?, ¿que no hubo suficiente transferencia desde la investigación hacia la enseñanza?, ¿que los ámbitos académicos funcionaron de espaldas a la sociedad? En efecto, no se puede eludir las responsabilidades que les caben a los geógrafos en la conceptualización que la sociedad tiene de ellos, aunque el proceso en la formación de idearios es muy complejo e intervienen múltiples factores. Tampoco en la baja trascendencia social alcanzada por la disciplina actualmente, dado que la ciencia geográfica “...mantiene una escasa visibilidad social..." y presenta "...frecuentes dificultades para que la sociedad identifique sus competencias y capacidades..." (Méndez, 2008, pp. 129, 131). En este sentido Segrelles (2005, p. 1) sostiene que es el "...escaso arraigo de nuestra disciplina en la sociedad, lo que conduce a un desconocimiento profundo y generalizado acerca del quehacer geográfico, ignorancia que no sólo afecta a los ciudadanos, sino que también puede hacerse extensiva a muchos científicos sociales".

Si consideramos que el objeto de estudio de la geografía es el espacio geográfico, debemos aceptar que se trata de un campo en el que todos juegan. El espacio terrestre es el ámbito en el que dirimen, compiten, trabajan y ejercen poder todas las disciplinas científicas; ellas, directa o indirectamente, ya sea a través de contenidos, aplicaciones o ejemplos, toman elementos, fenómenos, factores, problemas y datos del espacio terrestre que son tratados desde sus propios intereses, objetivos, necesidades y métodos. Ello da pie a que muchos consideren que no es una condición necesaria poseer el título de geógrafo para hacer (enseñar, investigar, aplicar) geografía.

Ante esta realidad no es aconsejable aislarse, sino interactuar con las otras disciplinas (no verlas como intrusas cuando convergen en algunos temas, asuntos, tratamientos o problemas que poseen expresión espacial). Es beneficioso que los demás campos del conocimiento estén al tanto de lo que saben hacer los geógrafos, cómo trabajan y qué son capaces de aportar. Por cierto, "una de las novedades a destacar en las dos últimas décadas es la incorporación al trabajo de los geógrafos de determinadas temáticas transversales, necesariamente transdisciplinares, que se adaptan bien a esas propuestas de avance en la dirección de una ciencia de la complejidad" (Méndez, 2008, p. 143).

Un rasgo distintivo y, a la vez, una fortaleza de la ciencia geográfica es que el énfasis puede ponerse en distintos aspectos de la misma realidad geográfica, es decir que, mientras un geógrafo se interesa por las distribuciones existentes en un espacio, su colega puede estar ocupado en visualizar las relaciones allí presentes, al tiempo que un tercero prioriza la organización o el proceso de construcción de ese territorio y, otro, se inclina por el abordaje integrador y la síntesis geográfica. Ello no constituye una dificultad o una dicotomía, por el 
contrario, cada uno contribuye con una mirada distinta capaz de enriquecer la comprensión de ese ámbito geográfico.

Pero hay un aspecto aún más relevante de la geografía, manifiesto mayormente desde mediados del siglo XX y consolidado a partir de los años ochenta, como es el surgimiento, reaparición o metamorfosis de distintas perspectivas o enfoques geográficos, que han delineado caminos innovadores para acceder al objeto de estudio de la disciplina. Este florecimiento de corrientes diversas concebidas en el interior de la geografía ha provocado preocupación, incluso cierta zozobra en algunos geógrafos, en tanto para otros ha generado expectativas y renovadas esperanzas. Tales enfoques (geografía general y sistemática, regional, cultural, cuantitativa, sistémica, ambiental, de la percepción y el comportamiento, radical, humanista, automatizada) equivalentes a diferentes modos de abordar la compleja realidad geográfica desde distintos paradigmas, marcos teóricos, métodos y herramientas, le otorgan una riqueza extraordinaria a la geografía, pues le permite estudiar, analizar, interpretar y comprender el espacio geográfico, mirando aspectos disímiles de él, incluso desde pedestales ideológicos, filosóficos y epistemológicos diferentes. Esa posibilidad le otorga consistencia a la labor geográfica e, incluso, ofrece la oportunidad de identificar puntos de encuentro entre los enfoques, es decir, miradas complementarias, integrales y totalizadoras del espacio geográfico. Consiguientemente, espacios diversos, dinámicos y complejos como los que observamos en nuestro mundo actual, nos invitan e interpelan a desarrollar un trabajo multiperspectivo.

Las transformaciones territoriales surgidas o potenciadas a partir de la segunda mitad del siglo XX desafían a incorporar concepciones más abarcativas, multitemporales, multiculturales y semióticas del espacio, a estudiar verdaderas encrucijadas que los geógrafos no veían hasta hace poco tiempo y que, consecuentemente, les imposibilitaba pensar, reflexionar, interpretar y resolver los problemas que se erguían frente a ellos. Sin embargo, otras disciplinas como la sociología, la antropología y la ciencia política fueron más perceptivas, empáticas y comprometidas, involucrándose con las problemáticas sociales y culturales, mientras los geógrafos idiográficos seguían jugando a la región y los neopositivistas a la cuantificación.

En razón de la amplitud que posee el objeto de estudio de la geografía, desde otras disciplinas pueden suponer que "el que mucho abarca, poco aprieta", pero existe otra manera de apreciar este rasgo de la geografía, que descansa en la actitud que asumen los geógrafos en relación con dicho objeto y que puede sintetizarse en la siguiente expresión: "apretando todos juntos (como comunidad disciplinar) y de diferentes maneras (desde diversas perspectivas o enfoques), es posible abarcar mucho (lograr amplitud y excelencia en la producción geográfica)". 
Un primer escollo por superar en el quehacer de los geógrafos del siglo $\mathrm{XXI}$ es el peso de la tradición. Una abrumadora mayoría de geógrafos recala en la docencia en sus distintos niveles (cuenten o no con esa vocación), tal como lo expresa Amorós: “...hay maestros para quienes la Geografía no es más que un medio, mientras que para otros es un fin en sí misma” (2002, p. 76). La investigación se desarrolla fundamentalmente en los ámbitos universitarios, organismos de investigación, entes gubernamentales y privados, en tanto, otras funciones como consultorías, asesoramiento o prestación de servicios concretos, se desarrollan en forma particular o en el marco de empresas, colegios profesionales, universidades, instituciones de investigación u organizaciones no gubernamentales.

Con respecto al rol de los geógrafos, Reboratti (2001, p. 125) expresa que "Pocas veces se cumple el sueño de la tan mentada (y teórica) habilidad del geógrafo para dirigir equipos interdisciplinarios. Las más de las veces la tarea es más modesta y posiblemente más específica".

En Argentina, la escasa presencia de los geógrafos en temas de aplicación (servicios, consultorías, asesoramiento, ordenamiento territorial, planificación, estudio y evaluación ambiental, etc.) tiene una explicación cultural: las universidades y los centros de educación superior han formado tradicionalmente "profesores en geografía" para abastecer la demanda creciente de docentes, sobre todo en el nivel medio. Por esa razón, históricamente se ha asociado al geógrafo con la enseñanza. La geografía se constituyó científicamente en las universidades: ellas fueron su hábitat inicial y, de allí, se expandió a los demás niveles educativos (en especial en la escuela media o secundaria), donde los geógrafos - con el paso del tiempo- se han sentido cómodos y contenidos, sin la necesidad de abrirse camino en otros nichos ocupacionales.

Es necesario tener en cuenta que, antes de la formalización del "oficio" de geógrafo, las universidades (y también los profesorados) se habían dedicado a formar al único geógrafo que se conoció por muchos años: el docente del secundario. Ése fue $-\mathrm{y}$ en buena medida todavía es- el único oficio que se imaginaba y que se aprendía en los institutos de formación superior, y todavía los profesores de geografía forman la corporación más numerosa en la disciplina, y la salida docente tiene suma importancia para las carreras universitarias. Los profesores de geografía, durante muchos años, se formaban con planes de estudio que se hacían a medida para los programas de enseñanza secundaria (Reboratti, 2001, pp. 122-123).

Sin embargo, aportar sus saberes en pro de organizar u ordenar un territorio debiera ser una constante entre los geógrafos, en convivencia e interacción con otras miradas disciplinares. 
La OT (Ordenación Territorial) es deudora de la Geografía en su necesidad de conocer con la mayor fiabilidad y objetividad posible qué es lo que se ordena, el territorio, tarea que tradicionalmente ha sido el campo de acción de la Geografía. El geógrafo es, sin duda, el profesional más capacitado para analizar la Ordenación Territorial... su aportación es imprescindible (Tapiador, 2001, p. 140).

Por cierto, a las restantes profesiones que operan con el espacio geográfico (vinculadas con el ambiente, el paisaje, el territorio, el espacio urbano y agrario, entre otros temas) les conviene enormemente que los geógrafos permanezcan atrincherados en el sistema educativo y no salgan a disputarles su trabajo en otros ámbitos profesionales. A tal punto se ha llegado que, en muchos países, los geógrafos no están colegiados, delegando así sus competencias a otros profesionales que sí lo están, como los ingenieros, agrimensores, arquitectos, abogados y economistas. Ello, desafortunadamente, priva a los geógrafos de oportunidades invalorables de participación y contribución en sus comunidades, regiones y países.

\section{La comprensión cabal del contexto}

Hasta que los geógrafos no logren entender plenamente los cambios que suceden en los contextos en los que se hallan insertos, sus actividades (tanto la enseñanza como la investigación y la aplicación) tendrán una elevada entropía y, en cierto modo, serán poco eficientes y hasta frustrantes. El mundo rígido, estructurado, de cambios más lentos y de bases materiales que ha caracterizado a la modernidad, hoy (en la posmodernidad) se mueve a mayor velocidad mostrando otras temporalidades y territorialidades en las que emergen fenómenos, procesos y factores que generan nuevas tensiones, desigualdades, asimetrías, inequidades, conflictos e injusticias, donde lo virtual y simbólico juegan un papel relevante. "La globalización y la era digital plantean un giro que trasciende a las realidades económica, científica, filosófica y educativa, llegando a afectar a la totalidad de la vida cotidiana" (Pallarès y Chiva, 2018, p. 835).

Debe aceptarse que la realidad (geográfica, territorial, regional, local) es dinámica y que los cambios se intensifican y aceleran; en consecuencia, es necesario adoptar una actitud pro activa, para evitar el aturdimiento y la inacción ante esa realidad caracterizada por la versatilidad. Es indispensable proceder con una mente abierta, dispuesta a interpretar los nuevos escenarios y situaciones que se generan en el espacio geográfico, desarraigar estructuras obsoletas de pensamiento, dogmas, preconceptos y prejuicios a fin de interpretar/comprender, tanto las peculiares organizaciones territoriales como las relaciones políticas, económicas y sociales que surgen cimentadas en constructos ideológicos, tecnológicos y culturales hasta hace poco tiempo desconocidos o inadvertidos. 
El panorama o contexto para los geógrafos presenta dos matices, uno desfavorable y, el otro, muy propicio. En cuanto al primero, se ha visto en muchos países -entre ellos la República Argentina- cómo en las últimas décadas los contenidos geográficos y la cantidad de horas cátedras han sido comprimidos, fragmentados y reducidos en la escuela media. En el currículo educativo, a partir de los años noventa, se le quitó espacios a la geografía para brindárselos a ciencias naturales, sociología, economía, ciencia política y derecho. En provincias como Chaco y Catamarca se han multiplicado extraordinariamente los institutos de formación docente de nivel terciario (superior no universitario), los cuales funcionan sin una relación estrecha con las universidades y, en su mayoría, ofrecen una formación disciplinar deficiente, desactualizada y carente de recursos técnicos como los SIG, la cartografía digital, los sensores remotos y otras herramientas de aprendizaje.

Por otro lado, los organismos estatales argentinos continúan, como usualmente lo han hecho, convocando a las profesiones tradicionales al momento de planificar obras que impactan sobre el ambiente, la población y el territorio y, por tanto, se repiten los errores producidos históricamente por la falta de abordajes integrales del espacio geográfico. No se puede entender que los geógrafos, pertenecientes al campo del conocimiento con más tradición en los estudios del territorio (Bozzano, 2009), estén ausentes cuando se trata de la organización del espacio. Ello es tan grave como prescindir de los ingenieros al diseñar y construir una represa hidroeléctrica. Afortunadamente, algunos pequeños avances se han logrado en los últimos años, como la incorporación de graduados en geografía en organismos del Estado y su contratación para realizar servicios específicos o consultorías en ministerios y municipios.

La realidad muestra, al menos en la República Argentina, que es más factible o probable que los geógrafos ocupen funciones jerárquicas en el ámbito de la educación, que en el campo de la planificación, el ambiente o el desarrollo territorial, tanto en los niveles nacionales como provinciales. Tampoco existe una demanda laboral significativa a nivel de los municipios o ayuntamientos.

Sin embargo, los retos geográficos que se erigen en la actualidad no pueden ser observados pasivamente desde una ventana. El desafío es la búsqueda de una coherencia filosófica, ontológica, gnoseológica y epistemológica que no admita ruptura, desconexión, ni alejamiento entre el geógrafo y el territorio, dado que geo significa tierra y grafo el que describe (estudia, analiza, resuelve), por tanto esta situación abre una gran posibilidad de acercamiento entre el geógrafo y el objeto de estudio de su disciplina, en la que el especialista de la "espacialidad terrestre" debe recuperar su nexo con la tierra y evitar navegar o divagar en, al menos, tres zonas de riesgo: 
la teoría carente de praxis, el abuso de los soportes tecnológicos y la praxis desprovista de teoría.

La problemática planteada trasciende lo disciplinar y engloba lo institucional: los organismos científicos, entre ellos las universidades, han creado en muchos países un sistema cada vez más burocrático en el que sus docentes-investigadores se hallan bajo una presión descomunal y estresante, determinada por una vorágine de evaluaciones y concursos que valoran exclusivamente el número de publicaciones en revistas especializadas e indexadas, los libros y capítulos editados, la cifra de ponencias en congresos, el número de becarios y tesistas que tutelan, la cantidad de proyectos de investigación en los que participan, dirigen o codirigen y una interminable lista de informes que deben presentar en tiempo y forma, sumados a la agenda de obligaciones académicas y administrativas que no ofrecen tregua.

Las instituciones, en especial las universidades, deben considerar que este sistema sólo fomenta que el académico sea un buen empleado administrativo, pues logra atarlo a la silla y soldarlo al monitor, convirtiéndolo en un perfecto oficinista. Esa es la manera más apropiada para impedir que los geógrafos se inmiscuyan en su entorno, en su realidad territorial, asuman compromisos y liderazgos y se planteen desafíos concretos y reales dentro de la sociedad que integran.

Las limitaciones enunciadas contrastan, felizmente, con el contexto favorable que se ha ido conformando en las últimas décadas a nivel global, en el que muchas sociedades (universidades, centros de investigación, grupos o redes de geógrafos, asociaciones, colegios profesionales, congresos, revistas) han sabido adecuarse, reorganizarse y brindar respuestas apropiadas a las demandas de este tiempo. Los últimos años se han tornado altamente propicios para que los geógrafos den el salto que merece la ciencia que cultivan. Se asiste a nuevos modos de hacer ciencia (virtualidad, conectividad global, producción colectiva sin barreras espaciales) y, como nunca en la historia de la humanidad, se cuenta con una extraordinaria facilidad, rapidez y abundancia de información que permite hacer más y mejores trabajos ahorrando tiempo y esfuerzo. Existen nuevas herramientas, técnicas, procedimientos, dispositivos, software y aplicaciones. Todo se ha hecho más veloz y más accesible: desde las computadoras personales o los teléfonos móviles, en segundos o minutos es posible hacerse de datos y publicaciones, consultar fuentes, bibliotecas y repositorios que tiempo atrás no existían o estaban vedados. Una verdadera revolución tecnológica y cultural ha modificado las formas de relaciones sociales, institucionales, académicas, grupales y personales.

La configuración de nuevas redes hace de la ciencia una acción más comunitaria, colectiva, global, integral y multianalítica que posibilita nuevas formas de producción y comunicación del conocimiento. Un ejemplo de ello 
ha sido la realización del X Congreso de la Ciencia Cartográfica y I Congreso Virtual Internacional organizados por el Departamento de Geografía de la Universidad Nacional del Nordeste (UNNE) y el Centro Argentino de Cartografía (CAC), desarrollados en plena pandemia de COVID-19 (4 a 6 de noviembre de 2020) que involucró a 62 expositores y 621 participantes de 23 provincias de Argentina y de otros 13 países, quienes conectados desde sus hogares posibilitaron que -durante las 33 horas de transmisión- varios miles de personas pudieran seguir simultáneamente todas las instancias del cónclave científico.

En este escenario global los geógrafos tienen dos opciones: a) "enredarse" con la magnitud de la información y recursos disponibles o; b) "redificarse" (edificar en red), es decir, utilizar, fortalecer, integrar y generar redes para que su trabajo sea más eficiente y productivo (Cuadra, 2013, p. 342).

\section{La toma de conciencia acerca del potencial de la disciplina y de los geógrafos}

Sin lugar a dudas, el trabajo de un geógrafo se tornará más eficaz en la medida que aprenda a transitar por las autopistas que hoy presenta la realidad geográfica en un mundo globalizado e interconectado que ofrece nuevas modalidades, medios y herramientas a la acción científica. Por tanto, en el siglo XXI los principios de localización, conexión, actividad, unidad y totalidad están más vigentes que nunca y los temas geográficos fluyen como ríos y eclosionan como hongos. Reboratti (2001) señala que los campos de trabajo para los geógrafos se centran principalmente en los sectores de la planificación territorial y sectorial, la aplicación de los Sistemas de Información Geográfica y la participación en estudios de impacto ambiental. Hoy se suman otros campos y problemáticas como el turismo, los emprendimientos inmobiliarios, el geomarketing, el desarrollo local, la movilidad (circulación y migraciones), la interculturalidad, la multiterritorialidad, las conflictividades, las desigualdades, la pobreza, la segregación espacial y la diversidad de minorías entre otros, además del amplio ámbito interdisciplinar de la geomática que involucra a las Tecnologías de la Información y la Comunicación (TIC), los Sistemas de Información Geográfica (SIG), la Teledetección, y la Infraestructura de Datos Espaciales (IDE).

Para que el rol de los geógrafos alcance la relevancia y el reconocimiento social pretendido, cada uno deberá asumir su trabajo con responsabilidad y pasión, abrazando el pedestal filosófico, ideológico y epistemológico con el que se sienta más cómodo y, desde allí, abordar los temas y desafíos de nuestro tiempo utilizando los saberes, métodos, técnicas, procedimientos, habilidades y herramientas disponibles. El capital necesario para tal fin es 
contar con una sólida formación disciplinar, pero con disposición a dialogar con los saberes extradisciplinarios.

Los cambios que actualmente se manifiestan en los espacios geográficos son, a su vez, generadores y reproductores de nuevas territorialidades (en las cuales emergen elementos, fenómenos y relaciones que hasta ahora eran ignotos) y conflictos sobre los cuales no se tenían registros (sea porque no existían o porque estaban latentes sin ser percibidos nítidamente), los cuales cobran dimensiones inusitadas en muy poco tiempo gracias a las tecnologías de la comunicación y son capaces de producir agudas crisis políticas y sociales (como las observadas en Barcelona, Hong Kong, Ecuador, Perú, Bolivia y Chile en 2019). También puede mencionarse el impacto de las ideologías políticas sobre el tejido social y el territorio (casos como los de Cuba, Venezuela y Nicaragua), los carteles del narcotráfico y su territorialidad invasiva y de extrema violencia (como se observa en México y Guatemala) o la conformación de grupos político-religiosos radicalizados de gran impacto territorial (en Siria, Irak, Etiopía, Somalia, Nigeria y República Centroafricana). Además, las dimensiones alcanzadas por el fenómeno migratorio ha generado espacios pluriculturales y multiterritorios en el interior de los países receptores, sobre todo en grandes urbanizaciones, donde es visible la coexistencia de distintas realidades que exigen una "comprensión dinámica", tanto del mundo como de los lugares. Un fenómeno paradigmático ha sido la pandemia de COVID-19 en 2020 y sus efectos globales-locales provocados en las áreas de salud, economía, educación, transporte, turismo, comunicación, etc. Todo esto significa que, para los geógrafos (y para los cultores de otros campos disciplinares vinculados con el territorio) hay mucho por aprender y un gran trabajo por hacer.

En consonancia con lo señalado precedentemente, existen numerosos trabajos que tratan sobre las dinámicas de la espacialidad en las últimas décadas, entre ellos: la desterritorialización y la reterritorialización (Haesbaert, 2004), la geografía del terrorismo y del petróleo, de los flujos y la circulación (Chiozza y Carballo, 2006), los contraespacios, las injusticias sociales y espaciales (Soja, 2010), el espacio como producto de relaciones y lugar de encuentro (Massey, 2005), el espacio como geometrías del poder (Massey, 1993) y la metamorfosis del espacio (Santos, 1995). Los geógrafos se encuentran hoy frente a problemas complejos y de difícil delimitación, extraordinaria y aceleradamente cambiantes en el espacio y en el tiempo, con multitud de interrelaciones en variadas escalas en las cuales juegan un papel decisivo, por un lado, las nuevas Tecnologías de la Información y la Comunicación (TIC) y, por otro, las concepciones y pautas culturales generadas en la llamada posmodernidad.

Entender y explicar hechos, fenómenos, relaciones y conflictos territoriales con fundamentos sólidos representa un gran desafío para los geógrafos 
de hoy. La guerra en Siria, el posicionamiento norcoreano frente a Estados Unidos, la situación política, económica y social de Venezuela y de otros países de América Latina, la explotación de los recursos naturales y el padecimiento económico y social sufrido históricamente por muchos países africanos, las pretensiones independentistas de Cataluña y Hong Kong, los fenómenos migratorios norteafricano-europeo y latinoamericano-estadounidense 0 la propagación vertiginosa de enfermedades a nivel planetario son solo algunas de las problemáticas de nuestro tiempo que requieren explicaciones y comprensiones geográficas e interdisciplinarias, pues las interpretaciones y relatos que provienen del análisis político, del ámbito periodístico y de los cultores de disciplinas en solitario resultan superficiales e insuficientes.

Actualmente los espacios locales son trastocados por decisiones de escala global impulsadas por organismos internacionales, gobiernos, empresas multinacionales e, incluso, por grupos cuya localización llega a ser desconocida o imprecisa. Observamos muchos ejemplos cuyas dinámicas territoriales son sorprendentes: espacios sin fronteras definidas en los que confluyen componentes ideológicos y tecnológicos que, apartados de toda ética, logran consumar sus fines, como los actos terroristas perpetrados en los últimos años por grupos radicalizados en ciudades europeas (París, Marsella, Manchester y Barcelona), la difusión de juegos virtuales orientados a adolescentes (que terminan con casos fatales en distintos puntos del planeta), las redes de narcotráfico, el comercio ilegal de armas y la trata de personas que dominan espacios y disputan poder territorial en distintas escalas.

Estas nuevas espacialidades imponen que la relación entre el investigador y el objeto de investigación deje de ser híbrida, distante, neutra, artificial $y$, por el contrario, se torne más significativa, influyente y comprometida al acceder a las problemáticas profundas de los sujetos, tales como el hambre, la discriminación, la degradación de la calidad de vida, la vulnerabilidad social, la violencia de género, la desterritorialización, la injusticia social, la segregación espacial y el delito, entre otras.

La complejidad, si bien es un atributo siempre presente en el espacio geográfico, ha tomado una dimensión especial en la posmodernidad. Globalización, tecnologías, giro cultural y ciberespacio (entendido como matriz electrónica que interconecta bancos de datos digitales a través de los sistemas computacionales reunidos en la red mundial) representan una nueva faceta de la espacialidad que desafía a los geógrafos y a los científicos en general. Las redes sociales son "el mundo" de las nuevas generaciones. "Cada lugar es, a su manera, el mundo." (Santos, 2000, p. 268). Como dice Blanco (2009, p. 37), se trata de "Un mundo que se mueve con distintas velocidades y que articula múltiples escalas".

El estado de la geografía en el presente muestra su virtud de permanecer y renovarse a través del tiempo, aunque desafortunadamente puede advertirse 
que, teniendo en cuenta su historia, sus temas y sus fines, no ha logrado el posicionamiento deseado dentro del tejido social y son varios los factores que frenan su desarrollo. La deficiente formación brindada por numerosos centros de formación superior no universitaria (en Argentina y otros países) es un factor que juega en contra de la disciplina y de los propios geógrafos. Son muchos los analfabetos tecnológicos que, en instituciones obsoletas, se esfuerzan por enseñar una geografía desactualizada a niños y jóvenes que crecieron jugando con las Tecnologías de la Información y la Comunicación (TIC). Esas falencias, sin embargo, no quitan que el escenario y el potencial que tienen los geógrafos ante sus ojos sean ilimitados. Felizmente, cada vez son más los geógrafos que dejan de lado el modelo memorístico, descriptivo y carente de compromiso territorial, para abordar los nuevos temas, problemas, métodos, herramientas y retos que en la actualidad interpelan a la enseñanza, a la investigación y a la aplicación, accediendo de ese modo a "una Geografía comprometida en la búsqueda de alternativas y la propuesta de soluciones" (Méndez, 2008, p. 151).

Entre los obstáculos existentes se advierte la miopía de gobernantes, técnicos y pedagógos que ha llevado a sacrificar y fracturar espacios y tiempos curriculares de este campo tan esencial en la formación identitaria y territorial de los ciudadanos, sobre todo en el ámbito de la escuela media. En las universidades y centros de investigación la geografía -en líneas generalesse ha mostrado fuerte y competitiva, aunque muchas ofertas curriculares han perdido vigencia y requieren una urgente actualización. La celebración de congresos regionales, nacionales e internacionales, los trabajos publicados en actas, libros y revistas científicas, el número de proyectos y programas disciplinares, interdisciplinares y transdisciplinares en los que los geógrafos participan -e incluso dirigen - nunca han sido tan cuantiosos como en el presente. Esa fuerza productiva e innovadora debería -tarde o tempranoderramarse y realimentar a los demás niveles educativos.

\section{El desafío de involucrarse en sus sociedades y comunidades}

Procurar que la disciplina se proyecte hacia el sitial más alto posible dentro del campo científico y que se la reconozca socialmente por sus aportes consistentes a los temas y problemas de nuestro mundo, es una responsabilidad moral y un deber intelectual de cada geógrafo. El mundo actual, abarrotado, tecnificado, hipercomunicado, cambiante, empequeñecido, ambientalmente impactado, económicamente frágil y socialmente injusto e incierto, requiere más que nunca la mirada holística o macroscópica, el análisis meticuloso, la síntesis integradora y las propuestas precisas que la geografía es capaz de dar sobre territorios, países, regiones, paisajes, ambientes, sitios y lugares. 
Parte de ese compromiso es ofrecerles a los alumnos, además de conocimientos rigurosos (contenidos, métodos, técnicas y herramientas), aquellos ámbitos propicios para el análisis, la reflexión, la crítica y el debate, tan necesarios para una comprensión cabal del espacio geográfico en cada uno de los niveles educativos. "La enseñanza de la Geografía debería contribuir a la formación de ciudadanos que realicen una mirada crítica a la realidad que nos rodea" (De la Calle, 2012, p. 32).

Dicha formación, más allá de que los estudiantes opten o no por ser geógrafos, debe contener suficiente sustancia para que, cuando les toque desempeñarse como docentes, directivos, funcionarios $u$ otras responsabilidades sociales, dispongan de ideas, capacidad de observación, elementos para el análisis reflexivo y crítico, conocimientos de fuentes e instituciones y de actores de referencia, tan indispensables para la toma de decisiones adecuadas a la hora de impulsar cambios que urgen sobre territorios y ambientes.

Los profesores de los niveles primario y medio deben tomar conciencia de que muchos de sus alumnos, aún aquellos que no se destacan demasiado, llegarán a ser profesionales, dirigentes políticos, empresarios y referentes sociales cuyas decisiones estarán vinculadas a la administración, la gestión, la economía, el ambiente, el derecho, la salud, la educación y la cultura, con implicaciones directas sobre la organización territorial, tanto a nivel local, como provincial, regional o nacional. Las capacidades docentes para transferir y desarrollar en los alumnos saberes, habilidades, prácticas y pensamiento estratégico sobre el espacio geográfico, en pocos años se verán reflejadas en planes, proyectos, acciones e intervenciones que impactarán sobre la vida social y las configuraciones territoriales. Lamentablemente, si los estudiantes no reciben una formación geográfica adecuada, igualmente llevarán a cabo las funciones inherentes a los roles sociales que asuman, y lo harán con los conocimientos y herramientas que dispongan, pero cometiendo graves errores, como los que actualmente observamos sobre el espacio geográfico, con efectos altamente negativos sobre la población, la economía y el ambiente.

Un compromiso genuino con el territorio debe llevar a los geógrafos a replantear su propio rol dentro del tejido social. Al loable desempeño en educación e investigación debe sumarse, en los próximos años, el fortalecimiento de las actividades en los ámbitos de la aplicación y de la participación comunitaria. Como ha sugerido Roccatagliata (1994), por mucho tiempo geografía y ordenación territorial recorrieron caminos diferentes y no se puede seguir dilatando esa necesidad de reencuentro.

En Argentina, el concepto erróneo que la gente suele tener acerca de los geógrafos y la débil contribución profesional de éstos fuera de los ámbitos educativos es, en gran medida, responsabilidad de los propios geógrafos. 
¿Cuántas veces los geógrafos presentan, ante organismos o funcionarios estatales, propuestas de mejoramiento de las condiciones territoriales o ambientales en las que viven? Los casos son excepcionales y suelen realizarse sólo cuando hay una demanda externa, es decir que no surgen como iniciativa del propio colectivo de geógrafos. Lo que se advierte, a menudo, son críticas intramuros que, a modo de desahogo o terapia, se socializan con colegas y alumnos o, circunstancialmente, a través de solicitadas en periódicos, sin mayor compromiso que el tiempo destinado a escribir esas líneas. Por otra parte ¿existen geógrafos que se desempeñen como intendentes (alcaldes), integren concejos municipales o se desenvuelvan en secretarías o direcciones de planificación comunal? En Argentina seguramente que no, o muy puntualmente, cuando la labor a escala local-comarcal es, probablemente, la ideal para aquellos geógrafos que desean volcar sus conocimientos en materia de planificación territorial, ambiente, producción económica, urbanización, ruralidad y problemáticas sociales.

Los países (regiones, estados o provincias) donde los geógrafos no han logrado (o querido) colegiarse, deberían pensar en hacerlo y no conformarse con la mera crítica hacia los ingenieros, arquitectos y urbanistas por lo que hacen, no hacen o deshacen frente a sus ojos. Las generaciones futuras de geógrafos señalarán la inacción y despreocupación de sus predecesores por no ubicar a la geografía en el sitial que le corresponde. Por cierto, no todos los graduados que aman la geografía tienen vocación para desenvolverse como profesores o investigadores, entonces ¿por qué cercenarles otras posibilidades profesionales?

Asimismo, un auténtico compromiso con la sociedad y con la propia disciplina implica estar muy informados y alertas, prestos a incorporar datos, ideas, conceptos, métodos, técnicas, herramientas y, además, reflexionar sobre los mismos en un mundo que se caracteriza por ser voluble, complejo y conflictivo. En el siglo XIX Ritter concebía al espacio geográfico como "... el teatro en el que se desarrolla la actividad del hombre..." (Estébanez, 1992, p. 26). En la actualidad, "eso" que llamamos espacio geográfico representa la coexistencia de distintas espacialidades (hechos, fenómenos, flujos y procesos con dinámicas temporales y comportamientos espaciales distintos que coinciden, convergen, se vinculan, conviven o se yuxtaponen en un mismo ámbito), máxime cuando los grupos humanos que lo habitan poseen diferencias culturales que dan lugar a cosmovisiones disímiles $\mathrm{y}$, por lo tanto, generadoras de conceptos, apreciaciones, valoraciones y prácticas divergentes sobre el espacio local (regional o nacional). 


\section{Discusión de los resultados}

Una de las contribuciones más importantes que el geógrafo puede hacer a la sociedad y a las comunidades (no tan comunes) que integran un territorio, es la de inculcar que un espacio geográfico es siempre heterogéneo (la homogeneidad es sólo una abstracción a cierta escala), diverso, diferenciado y que la convivencia es producto de actitudes tolerantes, diálogos, consensos, acuerdos y negociaciones entre sus habitantes (actores sociales). No entender esta cualidad del espacio, vale decir su complejidad, lleva a que las sociedades, muchas veces, se estanquen en conflictos irresolubles, en dicotomías, dilemas, intolerancia y violencia cuyo denominador común es la injusticia social y espacial. El momento histórico actual exige conocer profundamente qué sucede en la aldea global, indagar qué acontece más allá de nuestras fronteras (las cuales no suelen ser meramente políticas, sino mentales, disciplinares y culturales), pero a la vez, mantener lazos firmes con la realidad geográfica cotidiana, es decir, con las escalas local, provincial, regional y nacional.

La participación del geógrafo en un territorio puede tener carácter "profesional", cuando es convocado como consultor, asesor o integrante de un grupo de trabajo estatal, universitario o privado destinado a planificar un territorio $u$ ofrecer un determinado servicio. Pero hay otra modalidad de participación, que podría llamarse "comunitaria", en la que el geógrafo une sus cualidades de ciudadano comprometido con la de sus saberes específicos, por ejemplo a través de la elaboración de propuestas escolares, barriales, de grupos o sectores sociales movidos por inquietudes, preocupaciones 0 expectativas existentes en el colectivo social. El cultivo de una "geografía cotidiana" es muy fructífero para la disciplina, pero ello implica asumir roles, retos y obligaciones con el lugar que se habita y/o trabaja, más allá de que la tarea desempeñada fuese la docencia, la investigación o la aplicación. La formación que tiene el geógrafo le brinda elementos suficientes para opinar con fundamentos, enseñar, proponer, involucrar a estudiantes y vecinos, tomar contacto con las autoridades ante problemáticas o decisiones políticas que tengan impactos directos sobre el entorno, capaces de afectar la calidad de vida de la población o producir algún tipo de injusticia espacial.

Aquel geógrafo que cuenta con una buena formación en la disciplina está capacitado para detectar el desorden, las carencias, la falta de relaciones, los desequilibrios y los conflictos que se manifiestan en un territorio. Dispone de recursos cognoscitivos, metodológicos y técnicos para averiguar las causas o factores que los originan y analizar alternativas posibles tendientes a superar las problemáticas existentes, en vistas a una mejor calidad de vida de los habitantes. En la enseñanza, es menester involucrar a los alumnos en la identificación de problemáticas nacionales, regionales y locales, en la detección de riesgos potenciales (elaboración de diagnósticos), en 
la formulación de objetivos y metas, en el análisis del modelo actual del territorio, en reflexiones sobre el modelo deseado y en la elaboración de planes (prognosis) que se puedan socializar, debatir y enriquecer para propulsar acciones junto a los diferentes actores territoriales.

Entender el territorio supone describirlo, interpretarlo y explicarlo mediante la co-construcción de saberes científicos y de otros saberes, encontrar ...sus... qué y sus por qué...; Quienes entiendan el territorio, quienes puedan hacerlo más inteligible, estarán en mejores condiciones de intervenir, de gestionar, de contribuir a desarrollarlo, a transformarlo, a ser más inteligentes con su territorio (Bozzano, 2012, p. 3).

Debe reconocerse que, en los últimos años, la participación de los geógrafos fuera de los ámbitos educativos y de la investigación ha experimentado un leve incremento y mayor visibilidad, por un lado, gracias a la utilización y propagación de los SIG, los progresos en materia de IDE (Infraestructura de Datos Espaciales) y la existencia de mayores demandas por parte de los Estados y de los sectores empresariales. Las mismas suelen estar dirigidas a profesionales particulares, pero en ocasiones las propias universidades son buscadas con el propósito de que sus equipos de geógrafos o sus grupos interdisciplinarios brinden los servicios específicos que se requieren. Por otro lado, la presencia de geógrafos comprometidos con distintas problemáticas sociales (pobreza, exclusión, movimientos sociales, violencia de género, minorías, etc.) también es creciente, lo que representa un paso muy importante para la disciplina, aunque todavía insuficiente.

Cuando se trata de planificar, organizar, modificar o transformar el espacio geográfico o el territorio, o algún componente del mismo, resulta muy eficaz el trabajo del geógrafo junto a especialistas de otras disciplinas: la geografía no puede resolver todo, pero tampoco merece estar ausente en esta temática tan vinculada con su objeto de estudio. "El territorio se propone así como un eje a partir del cual podrían plantearse adecuadamente ciertos problemas y estimular la colaboración interdisciplinaria" (Capel, 2016, p. 15).

La geografía es una ciencia humana (social y cultural) portadora de responsabilidades y valores enlazados con las vivencias cotidianas y con los problemas que enfrentan y sufren los sujetos y las comunidades en todos los lugares de nuestro planeta. Como tal, sus cultores deberían ser las voces cantantes de aquéllos que no tienen voz o carecen de los saberes necesarios ante situaciones que afectan sus ecosistemas, ambientes y territorios (suelos, aguas, aire, plantas, animales y seres humanos). A los geógrafos la sociedad les brinda, a través de sus instituciones, una formación holística, integral, analítica, técnica y de gran capacidad de síntesis, asimismo las herramientas y metodologías para aplicarlas a situaciones reales de un territorio, de modo 
que sus acciones no deberían acabarse en el trabajo de cátedras, proyectos de investigaciones, conferencias, congresos o defensas de tesis. Existe un compromiso social que hoy, por lo general, se encuentra minimizado en la escala local. Denunciamos cuestiones mundiales o regionales -ello está muy bien-, pero en el barrio o ciudad vivimos de incógnito. Un geógrafo bien formado académicamente tiene la capacidad de comprender la configuración de un espacio geográfico, detectar las justicias e injusticias existentes en un territorio y analizar la vulnerabilidad de un ambiente ante determinadas prácticas productivas no sustentables, sin embargo no es común que éstas se pongan en evidencia o sean denunciadas pública o judicialmente. Para saldar esta deuda con nuestras comunidades, los geógrafos deberíamos erigirnos, en nuestros barrios, pueblos, ciudades, ámbitos rurales, comarcas, regiones y países, en "porta voces" sin ser periodistas, en "defensores del pueblo" sin ostentar esa función política y en quienes "dan el grito de alerta" sin ser soldados, cuando está en juego - nada más, ni nada menos- que el equilibrio de nuestros ecosistemas, la salud y calidad de vida de la población o la exclusión de nuestros semejantes.

\section{Conclusiones}

Es importante, para la geografía y para sus cultores, reflexionar a menudo sobre el rumbo que toma la disciplina y el rol que le cabe a los geógrafos dentro del contexto imperante. La autocrítica constituye una virtud a veces dolorosa e incómoda, pero a la vez imprescindible para reencaminar pensamientos y acciones y, también, para trazar nuevos objetivos y rumbos. Comprender el contexto en el que nos movemos es indispensable, como lo es la toma de conciencia acerca del potencial de la disciplina, la naturaleza del quehacer de los geógrafos y el compromiso de involucrarse en las comunidades y territorios.

El encierro de los geógrafos en el ámbito de la enseñanza y, más tenuemente, en la investigación no ha dejado mucho margen para desarrollar sus competencias en el campo de la aplicación, situación que propició la colonización de otras disciplinas en temas y actividades inherentes al campo de acción de la geografía. A raíz de ello, suele haber una gran distancia entre lo que el geógrafo "dice ser" y lo que en realidad "es"; entre lo que expresa "saber hacer" y lo que realmente "puede hacer"; entre el rol profesional que reclama y el reconocimiento y aceptación social que recibe. Esta situación nos lleva a replantear, en primer término, la necesidad de reforzar la formación del geógrafo en muchas universidades y centros de formación superior no universitaria de Argentina (y posiblemente de muchos países): revisar los planes de estudios vigentes (la solidez teórica, metodológica e instrumental que ofrecen, el perfil y las competencias del graduado y los alcances del 
título) y promover la calificación de sus recursos humanos. En segundo lugar, procurar que las investigaciones que se proyecten tengan impactos perceptibles en el tejido social y, finalmente, trabajar arduamente para abrir puertas (promover la inserción de los geógrafos) en el ámbito de la geografía aplicada (organismos estatales, empresas y organizaciones privadas).

En la actualidad, el campo del conocimiento geográfico se presenta sumamente dinámico debido a la confluencia de variados factores. Nuestro planeta nunca ha tenido tanta población como en el presente, por lo tanto, los altos niveles de consumo (alimentos, ropas, medicinas, energía, insumos de todo tipo, transportes, turismo, etc.) no tienen precedentes, como tampoco la demanda de recursos tecnológicos destinados a la producción primaria, la industria, el comercio, las comunicaciones, los transportes, la salud, la educación, la seguridad, los servicios y las restantes actividades económicas que adquieren cada vez más diversificación y especialización.

El espacio geográfico, en consecuencia, aumenta su complejidad, las ciudades multiplican sus habitantes, ensanchan sus dimensiones, al tiempo que crecen las demandas y conflictos; ciertos recursos naturales se agotan, los ambientes sufren deterioros, a la vez que se instalan nuevos patrones culturales que hacen que las sociedades y territorios experimenten grandes y vertiginosas transformaciones. Muchos territorios, que hasta hace poco tiempo gozaban de un orden o equilibrio, hoy dan muestras de desordenamiento. Comprenderlos, habitarlos, gestionarlos y transformarlos no resulta sencillo. Estos rasgos tan notorios de la posmodernidad también complican la vida y el quehacer de los geógrafos investigadores, los interpela como especialistas de la "lugaridad", los desafía a salir de los cómodos gabinetes climatizados, a abandonar el trabajo lábil, neutro y sin compromisos y escoger nuevos temas y problemas de la realidad, involucrarse con ellos, incorporar ideas innovadoras y renovar los métodos, técnicas y herramientas, es decir, entrar en zonas de riesgos e incertidumbres sumando nuevas preocupaciones que, seguramente, harán que su trabajo sea más eficaz, relevante y valorado.

Un mundo saturado de datos e información simultánea requiere, como nunca, la síntesis integradora que los geógrafos - mejor que nadiesaben lograr. Desde la docencia es invalorable la influencia que se puede ejercer en las jóvenes generaciones, por ejemplo, comprometiéndolas con el uso apropiado de los recursos naturales, el desarrollo sustentable, la equidad social, el desarrollo integral (no meramente económico) del territorio, el ejercicio de los valores, la preservación de los patrimonios naturales y culturales y la visión democrática de una construcción social genuinamente participativa capaz de elevar la calidad de vida de la población actual y de las próximas generaciones. En tal sentido, es importante reducir el abismo entre la ciudadanía y el poder político en el marco del sistema democrático. Desde la docencia y la investigación 
geográfica es posible propiciar ámbitos de participación, ejercitar la toma de decisiones, elaborar planes y programas, asumir roles, generar contactos con profesionales y dirigentes políticos, debatir ideas, etc. Naturalizar estas prácticas redundará en que alumnos, vecinos y ciudadanos en general incorporen conocimientos, actitudes, habilidades y procedimientos responsables y comprometidos con su realidad cotidiana, con su entorno, su región y su país. Plantear y exigir el orden espacial más justo y reclamar acciones que conduzcan a una mejor calidad de vida son derechos ciudadanos que deben promoverse desde la geografía (ciencia formadora de identidad territorial). Entonces ¿por qué aceptar la vulneración de derechos?, ¿por qué admitir silenciosamente la instalación de basurales en cercanías de lugares habitados?, ¿por qué soportar resignadamente que las industrias generen ruidos y dispersen partículas dañinas para la salud de los ciudadanos?, ¿por qué no reclamar y proponer la relocalización de depósitos de materiales tóxicos situados dentro de una planta urbana?, ¿por qué no hacer encuestas para conocer lo que los habitantes prefieren o rechazan de su entorno y plantear un orden espacial más satisfactorio?, ¿por qué permitir que un municipio autorice derribar antiguas edificaciones de alto valor histórico, cultural, patrimonial e identitario en una localidad?

Asimismo, el campo de la aplicación, tan dejado de lado por los geógrafos en muchos países, hoy aparece como una alternativa profesional que encuentra nuevas demandas en múltiples nichos de las estructuras estatales y de las organizaciones empresariales. Una sólida formación en cartografía automatizada, SIG, IDE, sensores remotos, estadística, geomarketing, probabilidad y programación les abre a los jóvenes geógrafos un amplio abanico de posibilidades laborales en temas ambientales, ordenamiento territorial, desarrollo local y regional, actividades productivas, etc. que no deberían desaprovecharse. En los lugares donde los geógrafos aún no se encuentran colegiados, urge ponerse en acción y bregar por la conformación de colegios profesionales que los nucleen y les otorguen el respaldo jurídico pertinente para llevar adelante tareas de consultorías, asesoramiento, contratos de servicios, etc.

Por último, retornamos a la pregunta efectuada por el Principito ¿qué es ser un geógrafo? Un geógrafo es muchas cosas a la vez: un caminante y navegante de nuestra Tierra, un observador de nuestro cielo, un intérprete de los paisajes, un analista de los hechos, situaciones y procesos, un maestro de lo cotidiano, un facilitador en la resolución de problemáticas humanas, un guardián de los ambientes, un denunciante de las desigualdades e injusticias espaciales, una voz autorizada en materia de organización territorial, un integrador de visiones interdisciplinarias, un reflexivo ante tantas corrientes heterogéneas. En síntesis... una persona preocupada y comprometida con su lugar, con su mundo y con el de quienes nos seguirán por generaciones 
y generaciones. La docencia en sus diferentes niveles, la investigación científica, la planificación estatal, el ámbito privado o no gubernamental y la participación comunitaria constituyen campos de acción donde los geógrafos pueden volcar sus saberes en vistas a un futuro mejor, vale decir, promover espacios más accesibles, más justos y más humanos.

\section{Bibliografía}

Amorós, M. (2002). Geografía y enseñanza secundaria (La educación de la mirada). Revista Investigaciones Geográficas, (29), 71-82, Instituto Universitario de Geografía, Universidad de Alicante, España. https://dialnet.unirioja.es/ejemplar/58462

Baulig, H., (1948). La géographie estelle une science? Annales de Géographie, LVII(305), 1-11, Université de Strasbourg, Strasbourg, France.

Berciano Villalibre, M. (1998). Debate en torno a la posmodernidad. Ed. Síntesis S. A.: Madrid, $216 \mathrm{pp}$.

Blanco, J. (2009). Espacio y territorio: elementos teórico-conceptuales implicados en el análisis geográfico. En Fernández Caso, M. V. y Gurevich, R. (Coords.), Geografía. Nuevos temas, nuevas preguntas. Un temario para su enseñanza (37-64), Ed. Biblos, Buenos Aires, Argentina.

Bozzano, H. (2009). Territorios posibles. Procesos, lugares y actores, Ed. Lumiere, Buenos Aires, Argentina, $635 \mathrm{pp}$.

(2012). El territorio usado en Milton Santos y la Inteligencia Territorial en el GdRI INTI. Iniciativas y perspectivas. 11th Annual International Conference of Territorial intelligence "Territorial intelligence and globalization tensions, transition and transformation", INTI HAL Archives-Ouvertes, La Plata, Argentina, pp. 12.

Capel, H. (1988). Filosofía y ciencia en la geografía contemporánea, Barcanova, Barcelona, España, $477 \mathrm{pp}$.

(2016). Las ciencias sociales y el estudio del territorio. GeoCrítica Biblio3W Revista bibliográfica de Geografía y Ciencias Sociales, XXI(1.149), 1-38. http://www.ub.edu/geocrit/b3w-1149.pdf

Chiozza y Carballo, C. (2006). Introducción a la Geografía. Universidad Nacional de Quilmes Editorial, Bernal, Buenos Aires, Argentina, $160 \mathrm{pp}$.

Claval, P. (2002). El enfoque cultural y las concepciones geográficas del espacio. Boletín de la AGE, (34), 21-39, Madrid. https://bage.age-geografia.es/ojs/index.php/bage/article/view/425/396

Cuadra, D., (2013). Teoría de la Geografía: reflexiones en torno a la identidad de la disciplina. Revista Perspectiva Geográfica, 18(2), 325-346.

DOI: https://doi.org/10.19053/01233769.2681

Daus, F. (1978). ¿Qué es la Geografía?, Ed. Columba; Buenos Aires, 71 pp.

De Saint Exupéry, A. (2008). El Principito, Ed. Salamandra, Barcelona, España, 96 pp.

De la Calle Carracedo, M. (2012). La enseñanza de la Geografía ante los nuevos desafíos ambientales, sociales y territoriales. Innovación en la enseñanza de la 
geografía ante los desafíos sociales y territoriales, Universidad de Valladolid, pp. 33-52, Valladolid, España.

https://ifc.dpz.es/recursos/publicaciones/33/36/03delacalle.pdf

Estébanez, J. (1992). Tendencias y problemática actual de la Geografía. Ed. Cincel, Madrid, España, 142 pp.

García Ballesteros, A. (1986). Teoría y práctica de la Geografía. Alhambra Universidad, Madrid, España, 371 pp.

George, P. (1979). Los métodos de la geografía, Oikos-Tau, Barcelona, España, 122 pp.

Gómez Mendoza, J. et al. (1982). El pensamiento geográfico, Ed. Alianza Univer-sidad, Madrid, España, 540 pp.

Gurevich, R. (2009), “Claves pedagógicas para un análisis geográfico”. En Fernández Caso, M. y Gurevich, R. (Coords.), Geografía. Nuevos temas, nuevas preguntas. Un temario para su enseñanza, (171-202), Ed. Biblos, Buenos Aires, Argentina.

Haesbaert, R. (2004). O mito da desterritorializaçao: do "fim dos territórios" á multiterritorialidade. Bertrand, Río de Janeiro, Brasil, 395 pp.

Haggett, P. (1994). Geografía. Una síntesis moderna, Omega, Barcelona, España, 696 pp.

Hartshorne, R. (1959). Perspective on the Nature of Geograplay. Monograph Series, Association of American Geographers-Rand McNally \& Company for the Association, Chicago, Estados Unidos, $201 \mathrm{pp}$.

Harvey, D. (1998). La condición de la posmodernidad. Investigación sobre los orígenes del cambio cultural. Ed. Amorrortu, Buenos Aires, Argentina, 408 pp.

Holt Jensen, A. (1992). Geografía. Historia y conceptos, Universidad de Bergen, Vicens Vives, Barcelona, España, 256 pp.

Lacoste, Y. (1976). La geografía: un arma para la guerra, Ed. Anagrama S.A., Barcelona, España, 160 pp.

Massey, D. (1993). Power-geometry and a progressive sense of place. En Bird, J., Curtis, B., Putnam, T., Robertson, G. y Tickner, L. (Eds.), Mapping the Futures: Local Cultures, Global Chance (59-69), Londres, Inglaterra.

- (2005). La filosofía y la política de la espacialidad: algunas consideraciones. En Arfuch L. (Comp.), Pensar este tiempo. Espacios, afectos, pertenencias, (101127), Paidós: Buenos Aires.

Méndez, R. (2008). Trayectorias recientes de la Geografía: algunos problemas y potencialidades para su enseñanza. Revista Huellas, (12), 128-155. http://www.biblioteca.unlpam.edu.ar/pubpdf/huellas/n12a08mendez.pdf

Ortega Valcárcel, J. (2000). Los horizontes de la geografía. Teoría de la Geografía, Editorial Ariel S.A., Barcelona, España, 604 pp.

Pallarès Piquer, M. \& Chiva Bartoll, Ó. (2018). El lugar del individuo en la era postpostmoderna. Sociedad, educación y ciudadanía tras la postmodernidad, en Revista Pensamiento, 74(282), 835-852.

https://revistas.comillas.edu/index.php/pensamiento/article/view/10731

Pickenhayn, J. (1994). Epistemología y Geografía, Ed. Plus Ultra, Buenos Aires, Argentina, $284 \mathrm{pp}$. 
Plans. P. et al. (1994). Introducción a la Geografía General, Ediciones Universidad de Navarra S.A., Pamplona, España, 556 pp.

Randle, P. (1977). Teoría de la Geografía, tomo I. Ed. Oikos, Buenos Aires, Argentina, 375 pp.

Reboratti, C. (2001). La Geografía profesional en Argentina. Documents d'anàlisi geogràfica, (39), 119-130, Universidad de Barcelona, Cataluña, España. https://core.ac.uk/download/pdf/13267809.pdf

Roccatagliata, J. (1994). Geografía y políticas territoriales. La ordenación del espacio, Editorial CEYNE, Buenos Aires, Argentina, pp. 131.

Santos, M. (1995). Metamorfosis del espacio habitado, Oikos Tau, Barcelona, España, pp. 118.

- (2000). La naturaleza del espacio. Técnica y tiempo. Razón y emoción. Editorial Ariel S.A., Barcelona, España, pp. 348.

Schaefer, F. (1953). Exceptionalism in Geography: A Methodological Examination. Annals of the Association of American Geographers, 43(3), 226-249, Washington D.C., Estados Unidos.

http://www.appstate.edu/ perrylb/Courses/5000/Readings/Schaefer_1953.pdf

Segrelles Serrano, J. (2005). El compromiso social y la ideología de la geografía: ¿desde la izquierda o desde la derecha? 40 Conferencia Internacional de Geografía Crítica (1-6), Ciudad de México. https://web.ua.es/es/giecryal/documentos/documentos839/docs/mexico.pdf

Soja, E. (2010). Seeking Spatial Justice United States of America, University of Minnesota Press, Minnesota, Estados Unidos, $256 \mathrm{pp}$.

Tapiador, F. (2001). El papel del geógrafo en las directrices de Ordenación Territorial, Boletín de la AGE, (31), 137-147, Madrid, España, https://bage.age-geografia.es/ojs/index.php/bage/article/view/391/362

Tuan, Y. (1974). Topophilia: a study of environmental perception, attitudes, and values, Prentice-Hall, New Jersey, Estados Unidos, 260 pp. 